\title{
EFFECT OF CADMIUM AS A WATER POLLUTANT ON THE FILTRATION RATE AND THE HISTOLOGY OF THE SIPHON OF THE MARINE CLAM VENERUPIS AUREA
}

\author{
Amaal Mohamadein and Mahmoud M. Desouky \\ Zoology Department, Faculty of Science, Zagazig University
}

Key words: Cadmium, filtration, siphon, histology, clams, Venerupis

\begin{abstract}
Cadmium is one of the most harmful environmental pollutants and has major toxicological effects on marine organisms. The present investigation was performed to study the effect of sublethal concentrations of cadmium on the filtration rate and siphon histology of the clam, Venerupis aurea. All applied concentrations of cadmium were found to inhibit the filtration rate of the investigated species. Histopathological studies revealed also that exposure to $300 \mathrm{ppb}$ of cadmium induced severe effects on the siphonal wall of the clam, which ultimately reduce the filtration rate. Firstly, it reduces the efficiency of the straining tentacles in preventing the entrance of large particles into the mantle cavity; secondly, it leads to contraction and shortening of the siphon that resulted in shortening of gill axis and reduction of interfilamentar space. This will reduce the power and capacity of the filter pump. Other histopathological effects of cadmium on the siphon were increased mucous secretion and constriction of the lumen that may affect the flow of water into mantle cavity. Moreover, it leads to necrosis of the outer and inner epithelia, derangement of muscle fibers and enlargement of blood lacunae.
\end{abstract}

\section{INTRODUCTION}

Observations of the behavioural response of the aquatic animals are relatively few compared with those describing direct toxic effects (Manley, 1983). Unlike many systems of potential value as indicators of sublethal toxic effect, the filtration rate of bivalves is based on an ecological response. Apart from taking oxygen and filtering food from water, bivalves also sort the suspended materials 
of non-food nature and settle them away. Filtration, in this sense, is very important with regard to the maintenance of the vital activities of the organism as well as from the viewpoint of water purification (Abel, 1976).

Furthermore, several features of the filtration process suggest its suitability for such application. The simplicity and small scale of the method offers economy in equipment and material, the short time required will allow labile pollutants to be tested without elaborate system to maintain the desired concentration, finally, the technique is considerably more sensitive than lethal tests (Abel, 1976).

The factors, which influence the filtration rate of bivalves, were studied. These include body size (Khaill, 1996); algal concentrations and size of particles employed (Winter, 1978; Griffith \& King, 1979); external factors such as temperature and oxygen supply (Salaki \& Lukacsovics, 1967) and water quality (Kraek et al., 1994). However, less attention has been paid to the effect of heavy metals on the filtration rate (Kadar et al., submitted).

On the other hand, Venerupis aurea is one of the commonly edible bivalves in Egypt. It is proved to be a suitable test animal: abundant along the shores, can be sampled all the year round and easy to maintain under laboratory conditions.

The objective of the present study was to clarify the effects of cadmium on the filtration rate and on the histological structure of the siphon, which is responsible for water flow over the gills and the mantle cavity, of the marine bivalve Venerupis aurea. This could lend support to the general harm of this heavy metal in the aquatic ecosystems.

\section{MATERIAL AND METHODS}

The commonly edible clam, Venerupis aurea was collected by enough number from a clean station of Suez Canal during January 1999. They were then transferred alive to the laboratory and allowed to acclimatize to the experimental set up for one week. They were kept at $20^{\circ} \mathrm{C}$ in static filtered seawater (salinity $36 \%$,). The water was aerated continuously and changed every other day. The unicellular green alga, Dunaliella marina (Dunal) was added as food. At the start of the expcriment, the cadmium was added to the experimental unit, each of 25 clams placed in a glass aquarium containing 5 liters of filtered seawater. The concentrations tested were 0 (control), 300, 500 
and $1000 \mathrm{ppb}$ using stock solution of $1000 \mathrm{ppm}$ of $\mathrm{Cd}$ (as $\mathrm{Cd} \mathrm{Cl}_{2}$, Aldrich). Water was renewed daily and cadmium was added again. After 48 hours of cadmium exposure, ten clams of equal size were selected from each aquarium and placed in $1 \mathrm{~L}$ glass beaker and replicated three times to determine the filtration rate. The clams werc fed on Dunaliella marina $\left(24000\right.$ cells $\left./ \mathrm{mm}^{3}\right)$. The algal concentration decreased due to the filtration activity. Three water samples $(5 \mathrm{ml})$ were then taken from each aquarium after $0,10,20,30,40,50$ and 60 minutes and fixed in 5\% Lugol's solution. The decline in algal concentration was measured using a haemocytometer. The filtration rate was calculated by using Coughlan's (1969) formula:

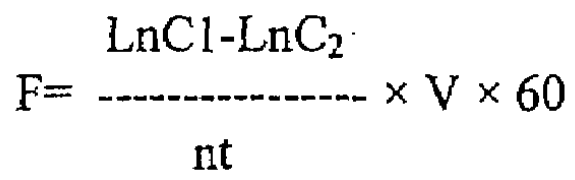

Where: $\mathrm{F}=$ Filtration rate $\left(\mathrm{ml} \mathrm{h}^{-1}\right.$ clam $\left.^{-1}\right)$

$\mathrm{C}_{1}=$ Initial cell concentration.

$\mathrm{C}_{2}=$ Final cell concentration after time $(\mathrm{t})$.

$\mathrm{t}=$ Duration of filtration measurement (minutes).

$\mathrm{V}=$ Volume of water.

$\mathrm{n}=$ Number of clams per each aquarium (10).

For scanning electron microscopy, pieces of the siphonal wall were fixed in $2.5 \%$ glutaraldehyde in $0.1 \mathrm{M}$ cacodylate buffer (pH 7.4). After rinsing in the same buffer. The specimens were critical point dried, gold- sputtered and viewed on Cambridge 350 SEM.

For histological observation, the siphons were dissected out from the clams that were treated with the lowest $\mathrm{Cd}$ concentration $(300 \mathrm{ppb})$. The specimens were fixed in $10 \%$ alcoholic formalin, dehydrated in ethanol, embedded in paraffin and sections were cut at $5 \mu$. The slides were stained in Hx \& E (Drury \& Wallington, 1980). Specific histochemical reactions were also employed. These include PAS- Alcian blue (Mowry, 1963) and bromophenol blue (Chapman, 1975).

Statistical analysis: Statistical significance at $p<0.05$ for each variable was tested using factorial analysis of variance. To detect differences between treatments the S-N-K multiple test was used. Calculations were made using SPSS (SPSS Inc, 1998). 


\section{RESULTS}

\section{Effect of cadmium on the filtration rate.}

Generally, all applied cadmium concentrations significantly decreased $(p<0.05)$ the filtration rate of the tested animals especially during the first 15 minutes after the addition of algae (Fig 1). The response was concentration dependent. The highest cadmium concentration had the highest effect while the relatively low concentrations were less inhibitory. After $20 \mathrm{~min}$. of addition of algae, the filtration rates were reduced to $57.99 \%, 62.96 \%$ and $71.56 \%$ of the corresponding control upon exposure to 1000,500 and $300 \mathrm{ppb}$ cadmium respectively. After $60 \mathrm{~min}$, the corresponding values were $27.30 \%, 35.62 \%$ and $66.46 \%$ respectively (Table 1 ).

\section{Histopathological effects of 300ppb cadmium on the siphon:}

The siphons are extensible, long and fused muscular tubes. They possess branching straining tentacles around the operatures (Plate IA). These tentacles may act to restrict the entrance of large particles (Hodgson, 1980) since the animal is normally littoral suspension- feeder occur in beeches where a considerable amount or organic debris may be brought into suspension by wave action.

Histologically, the siphon wall is surrounded by outer and inner cuboidal epithelia. Inside of the outer epithelium is a bed of connective tissue with many mucous glands (Plate IIIC). Beneath the inner epithelium is a second bed of connective tissue invested by heavy pigmentation that positively stained with both bromophenol blue (Plate IIC) and PAS (Plate IIIB). According to Hodgson (1980), this connective tissue is thought to be collagenous. Their arrangement around the exterior and interior of the siphon wall clearly serves to restrict any large increase in siphon diameter but at the same time allows the siphon to increase in length. The musculature comprises a thin layer of circular muscle to the inside of the outer connective tissue. This is followed by longitudinal muscle, which is the most dominant muscle and divided into blocks by circular muscle fibers (Plate IIC). Numerous haemocoelic lumina, one of them is larger than the rest, run longitudinally and divides the longitudinal muscle into outer and inner layer (Plate IID).

The siphonal wall was greatly affected upon exposure to $300 \mathrm{ppb} \mathrm{Cd}$ for $48 \mathrm{~h}$. The effects include swelling, enlargement of blood lacuna (Plate IIB), derangement of the muscle fibers and 
loosening of connective tissue beds that become in poor condition (Plate ID). These changes have ultimately resulted in swelling of the wall and constriction of the lumen (Plate IIB). Under SEM, the outer surface appears more folded due to the contraction of the siphon (Plate IB). The straining tentacles were greatly contracted and lose their branches (Plate IB). Other common histopathological changes were vacuolization and necrosis of the outer and inner epithelia (Plate IIIF \&H). The subepithelial mucous glands enlarge and move towards the outer surface indicating more secretions of mucous (Plate IIID). Under SEM, the openings of these glands appear larger and a considerable amount of mucous rushes from them to the outside (Plate ID\&E).

\section{DISCUSSION}

In marine water, the reported lethal effects of soluble cadmium compounds occur at a concentration over 95 ? $\mathrm{gl}^{-1}$ (Taylor, 1981) Thus, according to the GES- AMP Hazard profile system (Portmann, 1981), these materials would be considered to be highly toxic to aquatic ecosystem. The present investigation reveals that cadmium has seriously inhibited the filtration rate of the clam Venerupis aurea. It has an adverse action on the filtering activity, feeding, respiration and excretory processes that are reduced. Moreover, it affects both the living processes of the clams as well as their water-cleaning function, which is an important component with respect to maintenance of a healthy aquatic ecosystem (Kontreczky et al., 1997).

The mechanism by which cadmium reduces filtration rates is complex and several lines of evidences suggest that reduced filtration rate may be the result of severe effect of cadmium on the gills (Sunila, 1981, 1986, Da Ros et al., 1995). Cadmium was also proven to reduce the rate of shell opening (Sunila, 1981). Furthermore, the effects of cadmium on cellular metabolism are diverse. It replaces zinc in enzymes such as alcoholic dehydrogenase (Suzuki et al., 1991), reduces enzyme activities (Hilmy et al., 1985) or combine with nuclear compounds affecting transcription (Thiele, 1992).

However, the effect of pollutants on the siphon of bivalves is neglected despite its essential role in filtration. The present study indicated that the siphon is sensitive and vulnerable to cadmium. In this respect, Lukacsovics and Salanki (1968) found that the siphon is 
sensitive to various salts due to the presence of chemoreceptive epithelial cells, which may activate local neural circuits, resulting in activation or inhibition of the system responsible for water flow.

The role of mucous in regulation of metal uptake was established (Scott, 1989 and Jugdaohsingh et al., 1998), So, the increased secretion of mucous from the siphon wall may represent a defense mechanism against cadmium exposure.

It was also noted that cadmium exposure induces many severe effects on the siphon of the investigated species, which ultimately reduce the filtration rate. Firstly, it reduces the efficiency of straining tentacles in preventing the entrance of large particles into the mantle cavity. Secondly, the contraction of the siphon resulted in shortening of the gill axis and thus concurrently reduces the space between opposite bands of lateral cilia. So, the actively beating bands of cilia may interfere during their effective stroke (Jфrgensen, 1990). This might ultimately reduce the power and capacity of the filter pump.

\section{Legends of plates:}

\section{PLATE I:}

A: Scanning electron micrograph of the siphon of normal (control) clam showing the straining tentacles (St.T).

B: Scanning electron micrograph of the siphon of Cd-treated clam showing the straining tentacles (arrow) that contracted and lose their lateral branches.

C: Scanning electron micrograph of the siphon of normal (control) clam showing the outer surface with the mucous glands openings (mgo).

D: Scanning electron micrograph of the siphon of $\mathrm{Cd}$-treated clam showing increased secretion of mucous.

E: Magnified portion of (D) showing the mucous rushing from the pores of the mucous glands.

\section{PLATE II:}

A: T.S. of the siphon of normal (control) clam stained bromophenol blue.

B: T.S. of the siphon of Cd-treated clam stained bromophenol blue.

C: Magnified portion of (A) showing the histological structure of the siphonal wall. cm: circular muscle; ct: connective tissue; i ep: inner epithelium; Im: longitudinal muscle; p: pigmentation; o ep: outer epithelium. 
D: Magnified portion of (B) showing the dilation of blood lacunae and constriction of the siphonal lumen. $\mathrm{cm}$ : circular muscle; $\mathrm{ct}$ : connective tissue; bl: blood lacuna i ep: inner epithelium; l: lumen; Im: longitudinal muscle; p: pigmentation; o ep: outer epithelium.

\section{PLATE III:}

A: L.S. of the siphonal wall of normal (control) clam stained Alcian blue-PAS showing the presence of subepithelial mucous glands (mg).

B: L.S. of the siphon of Cd-treated clam stained Alcian blue-PAS showing that the subepithelial mucous glands enlarge and migrate towards the outer surface. Note the presence of heavy pigmentations beneath the inner epithelium. i ep: inner epithelium; m: mucous glands; p: pigmentations; o ep: outer epithelium.

C: Magnified portion of (A).mg: mucous glands

D: Magnified portion of (B). mg: mucous glands

E: L.S. of the siphonal wall of normal (control) clam stained IIx\&E showing the outer epithelium

F: L.S. of the siphon of Cd-treated clam stained Hx\&E showing vacuolization and nccrosis of the outer epithelium.

G: L.S. of the siphonal wall of normal (control) clam stained H\&E showing the inner epithelium.

H: L.S. of the siphon of Cd-treated clam stained Hx\&E showing vacuolization and necrosis of the inner epithelium (arrow head).

\section{REFERENCES}

Abel, P. D. (1976). Effect of some pollutants on the filtration rate of Mytilus. Mar. Poll. Bull., 7 (12): 228-233.

Chapman, D. M. (1975). Dichromatism of bromophenol blue with an improvement in the mercuric bromophenol blue technique for protein. Stain Technology, 50:25-30.

Coughlan, J. (1969). The estimation of filtering rate from the clearance of suspensions: Mar. Biol., 2: 356-358.

Da Ros, L.; Naci, C.; Campesan, G.; Menetto, A. and Stocco, G. (1995). Cadmium accumulation and biological effect of cadmium and LAS on gills of Mytilus sp. S. IT. E Atti, 16: 635-641. 
Drury, R. A. and Wallington E. A. (1980). Carlton's Histochemical Technique. $5^{\text {th }}$ ed. Oxford Univ. Press.

Griffiths C. L. and King J. A. (1979). Some relationships between size, food availability and energy balance in the ribbed mussel, Aulacomya ater. Marine Biology. 51: 141-149.

Hilmy, A. M.; Shabana, M. B. and Daabes, A. Y. (1985). Effects of cadmium toxicity upon the in vivo and in vitro activity of proteins and fine enzymes in blood serum and tissue homogenates of Mugil cephalus. Comp. Biochem. Physiol., $81(\mathrm{C}): 145-153$.

Hodgson, A. N. (1980). Aspects of siphonal activity and the effects of wounding and regeneration in some bivalve molluscs. Ph.D. thesis. The Univ. of Manchester.

Jprgensen, C. B. (1990). Bivalve Filter Feeding: Hydrodynamics, Bioenergetics, Physiology and Ecology. Olsen and Olsen. Pp 140.

Jugdaohsingh, R.; Cambell, M. M.; Thompson, R. P.; McCrohan, C. R.; White, K. N. and Powell, J. J. (1998). Mucous secretion by the fresh water snail Lymnaea stagnalis limits aluminium concentrations of the aqueous environment Environ. Sci. Technol., 32: 2591-2595.

Khalil, A. M. (1996). The influence of algal concentration and body size on filtration and ingestion rate of the clam, Tapes decussatus (L.) (Mollusca; Bivalvia). Aquaculture Research. 27: 613-621.

Kontreczky, C. S.; Farkas, J. A.; Nemcok, J. and Salanki, J. (1997). Short- and long- term effects of deltamethrin on filtering activity of freshwater mussel (Anodonta cygnea L.). Ecotoxicol. Environ. Safety. 38: 195-199.

Kraak, M. H.; Kuipers, F. Schoon, H.; de Croot, C. J. and Admiraal, W. (1994). The filtration rate of the zebra mussel, Dreissena polymorpha used for water quality assessment in Dutch rivers. Hydrobiologia, 294: 13-16. 
Lukacsovics, F. and Salanki, J. (1968). Data to the chemical sensitivity of freshwater mussel (Anodonta cygnea.). Ann. Biol. Tihan, 35: 25-34.

Manley, A. (1983). The Effect of copper on the behaviour, respiration, filtration and ventilation activity at Mytilus edulis. J. Mar. Biol. Ass. U.K., 63: 205-222.

Mowry, R. W. (1963). Alcian blue technique of histochemical study of acid carbohydrates. J. Histoch. Cytoch., 4:407.

Portman, J. E. (1981). Recent activities of the "GESAMP" working group on the evaluation of hazardous substances carried by ships. Ecotoxic. Env. Saf., 5: 56-71.

Salanki, J.; Lukacsovics, F. (1967). Filtration and oxygen consumption related to the periodic activity of freshwater mussel (Anodonta cygnea.). Annal. Biol. Tihany, 34: 8598.

Scott, J. E. (1989). In Symposia of the Society from Experimental Biology, NO 43. Mucus and related topics; Chantler, E., Ratchiffe, N. A., Eds., Society for Experimental Biology: Cambridge, pp 111-115.

Sunila, 1. (1981). Toxicity of copper and cadmium to Mytilus edulis L. (Bivalvia) in brackish water. Ann. Zool. Fennic., 18: 213-223.

Sunila, I. (1986). Chronic histopathological effects of short-term copper and cadmium exposure on the gill of the mussel, Mytilus edulis. J. Inverteb. Pathol., 47: 125-142.

Suzuki, K. I.; Kawahara, S.; Sunaga, H. and Kobayashi, E. (1991). Discriminative uptake of cadmium, copper and zinc by the liver. In "Metallothionein in Biology and Medicine", (ed. C.D. Klassen and K. T. Suzuki). pp 197-208. CRC Press, Boca Raton, F1. 
Taylor, D. (1981). A review of the lethal and sublethal effects of cadmium on aquatic life. In Proc. $3^{\text {rd }}$ Int. Cadmium Conference (Miami), pp 75-81 Cadmium Association, London.

Thiele, D. J. (1992). Metal regulated transcription in eukaryotes. Nucleic Acid Res., 20:1183-1191.

Winter, J. E. (1978). A review of the knowledge of suspension feeding in lamellibranchiate bivalves, with special reference to artificial aquaculture system. Aquacult., 13: 1133. 
EFFECT OF CADMIUM ON THE FILTRATION RATE AND 135 SIPHON OF THE CLAM VENERCPIS AUREA

\begin{tabular}{|c|c|c|c|}
\hline & \multicolumn{3}{|c|}{ Filtration rate (\% of control) } \\
\hline Time (min.) & $300 \mathrm{ppb}$ Cd & $500 \mathrm{ppb}$ Cd & $1000 \mathrm{ppb} \mathrm{Cd}$ \\
\hline 0 & 10.6 & 10.3 & 14.5 \\
\hline 5 & 12.60 & 12.54 & 12.32 \\
\hline 10 & 46.50 & 15.25 & 35.68 \\
\hline 20 & 71.56 & 62.96 & 57.99 \\
\hline 30 & 59.24 & 44.89 & 53.33 \\
\hline 40 & 80.88 & 48.93 & 51.45 \\
\hline 50 & 60.70 & 39.86 & 34.77 \\
\hline 60 & 66.46 & 35.62 & 27.3 \\
\hline
\end{tabular}

Table (1): Filtration rate (\% of control) related to time of Venerupis aurea after exposure to different concentrations of cadmium for 48 . 


\section{PLATEI}
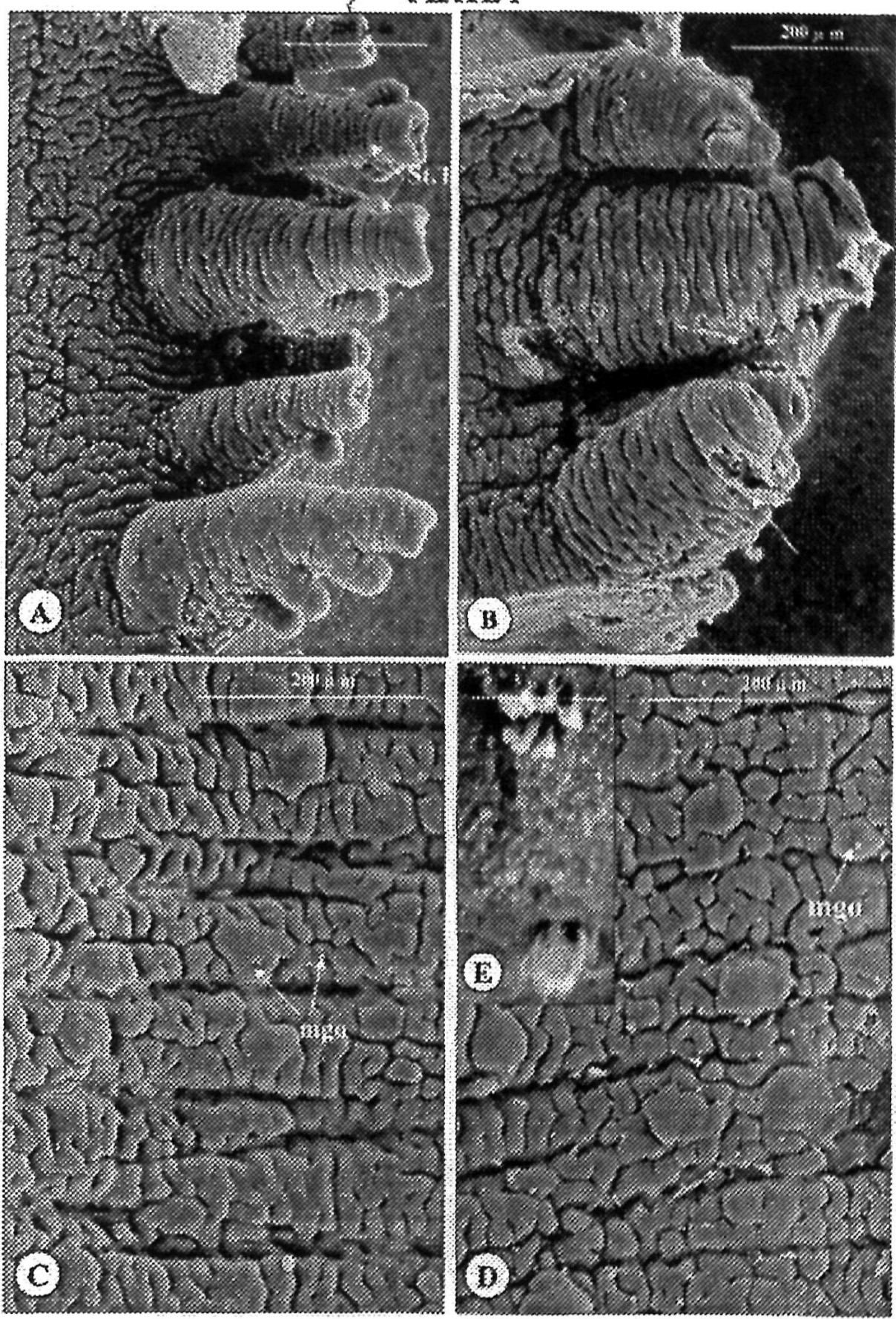


\section{PLATEII}

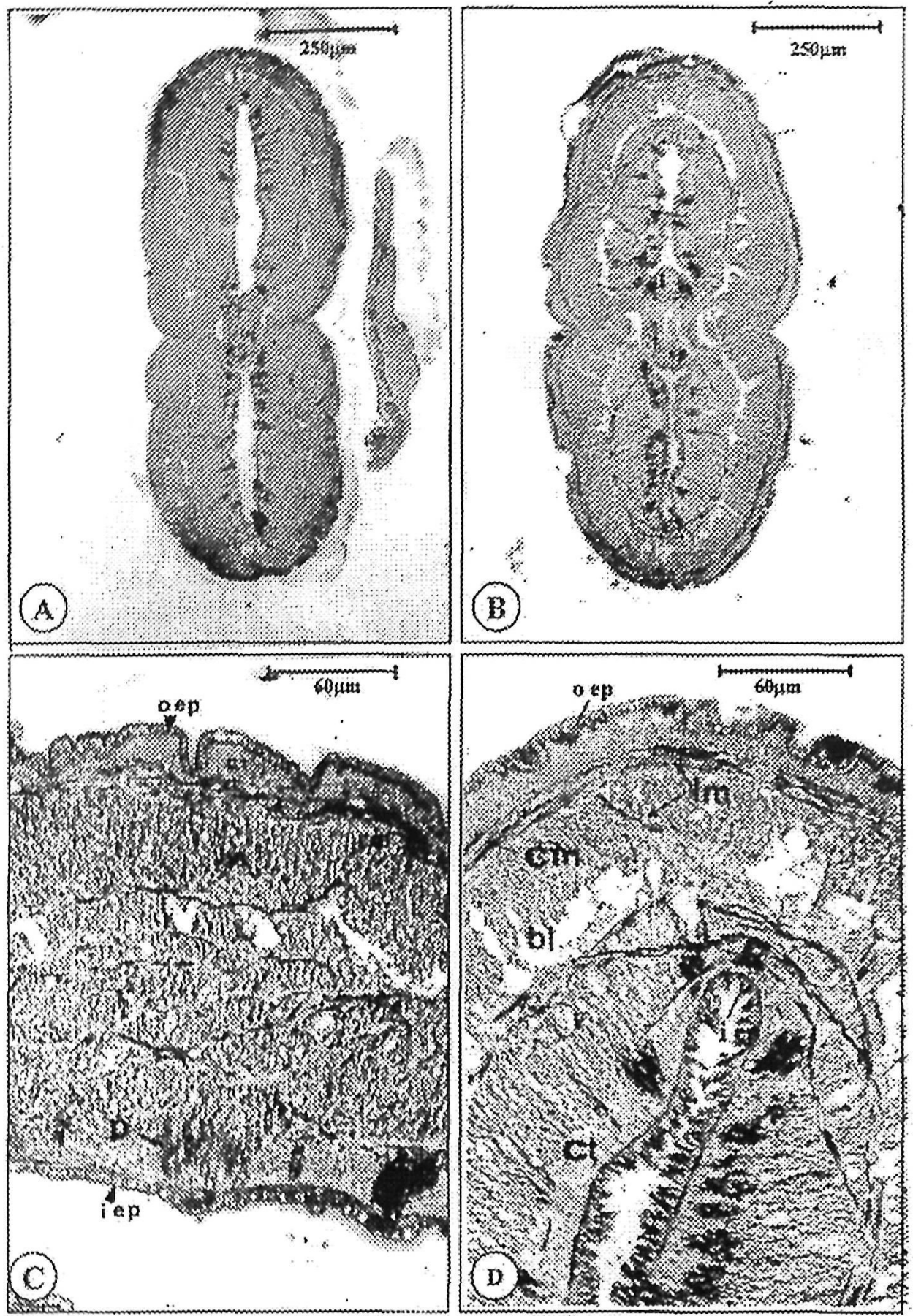

